Center for

Mathematical Economics

Working Papers

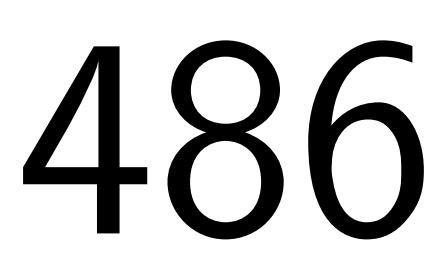

August 2013

\title{
Does size asymmetry exacerbate the inefficiency of tax competition?
}

Yutao Han, Patrice Pieretti and Benteng Zou

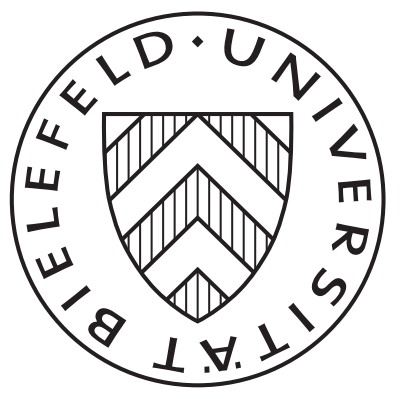




\title{
Does size asymmetry exacerbate the inefficiency of tax competition?
}

\author{
Yutao Han, Patrice Pieretti, Benteng Zou \\ CREA, University of Luxembourg
}

August 22, 2013

\begin{abstract}
Many authors demonstrate that the tax gap resulting from tax competition increases with the size asymmetry of the competing countries. Consequently, increasing country-size disparities exacerbates the inefficiency of tax competition. The aim of this note is to show that this classical view has no general validity if we consider that countries compete not only in taxes but also in the provision of infrastructure. The simple model we develop for this purpose demonstrates that the effect of size disparity on efficiency depends crucially on the degree of international capital mobility.
\end{abstract}

Keywords: tax competition, social welfare, inefficiency, infrastructure

JEL classification: H21; H73; F21

${ }^{*}$ Corresponding author: 162a, avenue de la Faiencerie, L1511 Luxembourg, Luxembourg. E-mail: yutao.han@uni.lu 


\section{Introduction}

The trend toward increased international integration results in higher capital and labor mobility, which, in turn, intensifies international competition for productive factors. The competing countries can differ relative to their population size, their initial capital endowments or their level of institutional development. Do these disparities between the competing jurisdictions damage global social welfare? Important contributions that address capital tax competition between asymmetric jurisdictions, such as those of Bucovetsky (1991) or Wilson (1991), demonstrate that larger countries choose higher tax rates than smaller countries because they face a relatively lower tax elasticity of capital and, hence, a lower marginal cost of public funds. As a result, equilibrium tax rates differ across states and lead to an inefficient allocation of capital (Wilson and Wildasin, 2004; Burbidge and Cuff, 2005; Boadway and Tremblay, 2011). Particularly, Kanbur and Keen (1993) analyze commodity tax competition when countries differ in population size. While reasserting the general result that smaller countries charge lower tax rates than larger countries, these authors demonstrate that increasing size asymmetry exacerbates the inefficiency of tax competition. In other words, increasing size inequality between jurisdictions makes tax competition more harmful.

Many authors argue that jurisdictions compete strategically and independently with respect to taxes and infrastructure expenditures (for example, Hindriks et al., 2008; Zissimos and Wooders, 2012 and Hauptmeier et al, 2012). The aim of this note is to show that inter-jurisdictional competition with tax and non-tax instruments may change the classical view regarding the detrimental effect of increasing country size disparities. In particular, we demonstrate that this view has no general validity and depends crucially on the degree of international capital mobility. 


\section{The model}

Consider two jurisdictions symbolized by $S$ and $L$ that compete for foreign direct capital. Population is evenly distributed, with a unit density, over the segment $[0,1]$. Country $S$ is assumed to be small in terms of total population. Its size is given by $s$, and $0 \leq s<1 / 2$. The size of the large country, $L$, equals $\frac{1}{2}<1-s \leq 1$. Similar to Pieretti and Zanaj (2011), we assume that each individual owns one unit of capital and is, at the same time, an entrepreneur and a worker. In other words, a one-person company is associated with each member of the population! While the entrepreneurs can move their activity abroad, we assume, similar to Ogura (2006), that they are heterogeneous in their preference to leave their current location. The entrepreneurs are thus ranked according to their willingness to relocate abroad. The closer an individual is to the border separating countries $S$ and $L$, the easier it is for the individual to relocate abroad. In other words, an entrepreneur of type $x \in[0,1]$ who moves abroad incurs a disutility $k|x-s|$. Here, $k>0$ is the unit cost of capital relocation, which will also be interpreted as the degree of international openness and $|x-s|$ is the "distance" between the border $s$ and the entrepreneur of type $x$.

\section{Firms}

As in Pieretti and Zanaj (2011), we introduce a linear technology in the following way. Each individual in country $j(j=S, L)$ is able to produce, with one unit of capital, $y_{j}=q+\theta_{j}$ units of one final good, where $q$ is the output share determined by the private sector $]^{2}$ and $\theta_{j}$ is the fraction depending on a public investment in country $j$. We assume that the final good is sold in a competitive market at a given price normalized to one. Because firms are free to move, location choices must be considered. The capital owners will set up their activity where profit, net of taxes and moving cost, is highest.

\footnotetext{
${ }^{1}$ It follows that the world population coincides with the population of firms. We could complicate the model by assuming that each firm is run by more than one person, but this would unnecessarily complicate the model without further insights.

${ }^{2}$ We assume that $q$ is large enough such that the net income of firms and the social welfare are always positive.
} 
Assume without loss of generality that the capital owner $x \in[0, s]$ living in country $S$ is indifferent toward producing at home or producing in the foreign country $L$ if

$$
q+\theta_{S}-t_{S}=q+\theta_{L}-t_{L}-k(s-x)
$$

where $t_{S}$ and $t_{L}$ are source-based tax rates levied on capital in countries $S$ and $L$, respectively.

It follows that

$$
x=\frac{1}{k}\left(\left(\theta_{S}-\theta_{L}\right)+\left(t_{L}-t_{S}\right)\right)+s .
$$

If $x>s$, firms move from the larger country to the smaller one, while firms move from the smaller country to its larger rival if $x<s$.

\section{Governments}

We now assume that the jurisdictions of $S$ and $L$ are able to increase, by appropriate public infrastructure expenditures, the productivity of all the firms located within their respective territories. As in Hindriks et al. (2008) and Pieretti and Zanaj (2011), we assume that one additional unit of public good produces one additional unit of private good. Consequently, the amount of public good supplied by jurisdiction $j(j=S, L)$ equals $\theta_{j}$. The cost of providing this public good in country $j$ is given by the quadratic cost function $C\left(\theta_{j}\right)=\frac{1}{2} \theta_{j}^{2}$. Each jurisdiction $j(j=S, L)$ is supposed to maximize its total tax revenue ${ }^{3}$, net of public expenditures, by choosing the appropriate tax rate $t_{j}$ and infrastructure levels $\theta_{j}$. The government's objective functions are thus given by

$$
B_{S}=t_{S} x-\frac{1}{2} \theta_{S}^{2}, \quad B_{L}=t_{L}(1-x)-\frac{1}{2} \theta_{L}^{2},
$$

\footnotetext{
${ }^{3}$ For a similar assumption, see Kanbur and Keen (1993), Zissimos and Wooders (2008), and Pieretti and Zanaj (2011).
} 


\subsection{Competition in taxes and infrastructure}

We now consider that the jurisdictions compete in taxes and infrastructure expenditures. To that end, we analyze a two-stage game $\AA^{4}$. First, the governments choose the level of infrastructure non-cooperatively and then, set the tax rates. Finally, firms decide where to locate their businesses. We solve the game backwards.

Starting from the second stage, each government chooses the tax rate that maximizes its objective assuming the rival's rate is given. The first order conditions yield the following unique equilibrium in tax rates

$$
t_{S}=\frac{1}{3}\left[k(1+s)+\theta_{S}-\theta_{L}\right], \quad t_{L}=\frac{1}{3}\left[k(2-s)+\theta_{L}-\theta_{S}\right] .
$$

After having substituted the above tax rates into the jurisdictions' objective functions, we can solve for stage 1 when governments compete for infrastructure expenditures $\theta_{S}$ and $\theta_{L}$. Solving the first order conditions leads to the unique equilibrium infrastructure expenditures

$$
\theta_{S}=\frac{6 k(1+s)-4}{3(9 k-4)}, \theta_{L}=\frac{6 k(2-s)-4}{3(9 k-4)} .
$$

Introducing (5) into (4) yields the equilibrium tax rates

$$
t_{S}=\frac{k[3 k(1+s)-2]}{9 k-4}, t_{L}=\frac{k[3 k(2-s)-2]}{9 k-4} .
$$

Imposing $\theta_{j}>0, t_{j}>0$ and $x \in(0,1)$ requires that $k>\underline{k}=\frac{2}{3}$. It is straightforward to see that, at equilibrium, the productivity of firms will be highest in the larger country and the tax rate will be lowest in the smaller country. Indeed, we have $\theta_{L}-\theta_{S}=$ $2 k \frac{1-2 s}{9 k-4}>0$ and $t_{L}-t_{S}=3 k^{2} \frac{1-2 s}{9 k-4}>0$ because $0 \leq s<1 / 2$. At equilibrium, we also show that $x-s>0$ where $x=\frac{3 k(1+s)-2}{9 k-4}$. In other words, the smaller country attracts a fraction of entrepreneurs coming from the larger jurisdiction by undercutting the

\footnotetext{
${ }^{4}$ The choice of sequentiality follows from the rule that the most irreversible decision must be made first.
} 
rival's tax rate even if it can provide attractive infrastructure. The larger country tries to resist the capital outflow by providing more infrastructure than its small rival.

\section{Size effect on social welfare}

As in Zissimos and Wooders (2008), we define efficiency as the maximum level of surplus available to all individuals in the two economies

$$
W=\left(\pi_{S}+\pi_{L}\right)+\left(B_{S}+B_{L}\right)-k \int_{0}^{|x-s|} y d y .
$$

The two terms in the brackets include, respectively, the joint firms' profits 5 and joint tax revenues. The last term is the companies' relocation costs.

We can write more explicitly that

$$
W=q+\theta_{S} x+\theta_{f}(1-x)-\frac{1}{2} \theta_{S}^{2}-\frac{1}{2} \theta_{L}^{2}-k \int_{0}^{|x-s|} y d y .
$$

For analytical convenience, we decompose social welfare in net global production $\left(\Psi_{1}=q+\theta_{S} x+\theta_{L}(1-x)-\frac{1}{2} \theta_{S}^{2}-\frac{1}{2} \theta_{L}^{2}\right)$ and total mobility cost $\left(\Psi_{2}=k \int_{0}^{|x-s|} y d y\right)$. Substituting the above equilibrium tax rates (6) and equilibrium public inputs (5) into (8), we obtain

$$
\begin{aligned}
W & =\Psi_{1}-\Psi_{2} \\
\text { with } \Psi_{1} & =q+4 \frac{\left(2 s^{2}-2 s+5\right) k^{2}-36 k+8}{(9 k-4)^{2}} \\
\text { and } \Psi_{2} & =\frac{1}{2} k(1-2 s)^{2} \frac{(3 k-2)^{2}}{(9 k-4)^{2}}
\end{aligned}
$$

It is interesting to discuss how the jurisdictions'size asymmetry can affect social welfare. First note that increased size asymmetry induces the smaller country to use

\footnotetext{
${ }^{5}$ The profit in country $j$ is $\pi_{j}=\left(q+\theta-t_{j}\right) x_{j}$, where $x_{S}=x$ and $x_{L}=1-x$.
} 
tax-dumping in a more aggressive way. Indeed, the tax differential $t_{L}-t_{S}$ increases when $s$ decreases. Accordingly, how do the competing jurisdictions change their attitudes toward infrastructure expenditures? Above we show that the large country reacts by augmenting its infrastructure supply in addition to lowering its tax rate, while the small country reduces its infrastructure expenditures. However, in the aggregate, infrastructure expenditures increase and as a result net global production $\left(\frac{\partial \Psi_{1}}{\partial s}<0\right)$ also increases. On the other hand, increasing size asymmetry exacerbates inter-jurisdictional competition and induces more capital to move. As a result, the welfare is negatively impacted $\left(\frac{\partial \Psi_{2}}{\partial s}>0\right)$. However, the sum of the two just highlighted effects is uncertain and depends eventually on capital mobility.

When capital mobility is high ( $\underline{k}<k<\widehat{k}$, with $\widehat{k}=\frac{1}{9}(2 \sqrt{7}+8)$ ), the positive impact of higher size asymmetry on global net production exceeds the negative effect of higher capital mobility. Consequently, the social welfare increases $\left(\frac{\partial W}{\partial s}<0\right)$.

If capital mobility is low $(k>\widehat{k})$, the opposite effect occurs $\left(\frac{\partial W}{\partial s}>0\right)$. In this case, capital is relatively captive and inter-jurisdictional competition is weak. It follows that the incentive to invest in infrastructure is low, and the effect on net world productivity is moderate. Because the unit cost of moving capital is high, the cost effect dominates the productivity effect and social welfare decreases. This result is consistent with the standard tax competition literature (see, for example, Kanbur and Keen, 1993), but it has no general validity

The following proposition concludes

Proposition 1 Inter-jurisdictional competition in taxes and infrastructure yields the following results:

(a) social welfare decreases with size asymmetry, if the degree of international openness is low, $k>\widehat{k}$;

\footnotetext{
${ }^{6}$ Our model reproduces the classical result if the jurisdictions are only uneven in size and only compete in taxes. The reason is that size asymmetry exacerbates capital mobility without overall output creation.
} 
(b) social welfare increases with size asymmetry, if the degree of international openness is high, $\frac{2}{3}<k<\widehat{k}$;

\section{Conclusion}

This paper shows that size disparity among competing economies has an ambiguous effect on overall social welfare when countries not only compete in taxes but also in infrastructures. The reason is that increasing size disparity impacts the intensity of interjurisdictional competition and thus influences the mix of policy instruments that are used to attract mobile capital. Basically, increased size asymmetry makes the smaller country more aggressive in undercutting its rival, and consequently, more firms will relocate their businesses. In standard tax competition models, relocation is uniquely wasteful as long as it does not induce (or is accompanied by) additional output creation.

\section{References}

[1] Broadway R. and J.F. Tremblay, 2011. Reassessment of the Tiebout model. Journal of public economics.

[2] Bucovetsky S., 1991. Asymmetric tax competition. Journal of urban economics 30, 167-181.

[3] Burbidge J. and K. Cuff, 2005. Capital tax competition and returns to scale. Regional science and urban economics 35, 353- 373.

[4] Hauptmeier S., F. Mittermaier and J. Rincke, 2012. Fiscal competition over taxes and public inputs. Regional science and urban economics 42, 407-419.

[5] Hindriks J., S. Peralta and S. Weber, 2008. Competing in taxes and investment under fiscal equalization. Journal of public economics 92, 2392-2402. 
[6] Kanbur R. and M. Keen, 1993. Jeux Sans Frontières: Tax competition and tax coordination when countries differ in size. American economic review 83, 877-893.

[7] Ogura L.M., 2006. A note on tax competition, attachment to home, and underprovision of public goods. Journal of urban economics 59, 252-258.

[8] Pieretti P. and S. Zanaj, 2011. On tax competition, public goods provision and jurisdictions' size. Journal of international economics 84, 124-130.

[9] Wilson J.D., 1991. Tax competition with interregional differences in factor endowments. Regional science and urban economics 21, 423-451.

[10] Wilson J. D. and D. E. Wildasin, 2004. Capital tax competition: bane or boon. Journal of public economics 88, 1065-1091.

[11] Zissimos B. and M. Wooders, 2008. Public good differentiation and the intensity of tax competition. Journal of public economics 92, 1105-1121. 